\title{
UN REPLANTEAMIENTO AL SIGNIFICADO DEL ACTIVISMO JUDICIAL
}

\author{
A RETHINKING AT MEANING OF JUDICIAL ACTIVISM
}

\author{
Julio César Muñoz Mendiola*
}

\begin{abstract}
RESUMEN: Este trabajo propone un replanteamiento a la forma de entender el activismo judicial, sobre todo, alejarlo de las críticas que se han gestado desde diferentes posiciones teóricas sin un sustento empírico fuerte, ya que en la práctica judicial ese activismo, en específico, el que se da en sede constitucional de última instancia, representa una vía institucional para la concretización de los derechos fundamentales y la sociedad democrática. Así, el activismo judicial al representar una consecuencia del control judicial tendrá una base institucional que es compatible con el diseño institucional del Estado Constitucional, pues ese diseño ha conferido discrecionalidad a los jueces constitucionales para concretizar el contenido de la Constitución.
\end{abstract}

ABSTRACT: This paper proposes a rethinking of the way to understand judicial activism, above all, away from the criticisms that have been developed from different theoretical positions without a strong empirical support, because in the judicial practice into definitive constitutional stage, that activism represents an institutional path for the realization of fundamental rights and democratic society. Thus, judicial activism, as consequence of judicial review, will have an institutional basis that is compatible with the institutional design of the Constitutional State, because that design has conferred discretion on constitutional judges to concretize the content of the Constitution.

PALABRAS CLAVE: activismo judicial, control judicial, magistratura constitucional, discrecionalidad, arbitrariedad.

KEYWORDS: judicial activism, judicial review, constitutional courts, discretion, arbitrariness.

Fecha de recepción: 24/06/2020

Fecha de aceptación: 15/09/2020

doi: https://doi.org/10.20318/universitas.2020.5870

* Licenciado y maestro por la Facultad de Derecho de la Universidad Nacional Autónoma de México (UNAM). Abogado constitucionalista y coordinador del Observatorio de Jurisprudencia en el Laboratorio de Derecho y Desarrollo Sostenible. http://orcid.org/0000-0002-8769-7984.

E-mail: julioderecho@comunidad.unam.mx 


\section{1.- INTRODUCCIÓN}

El activismo judicial se ha considerado como una manifestación de la discrecionalidad judicial, asimismo, se ha entendido desde diferentes posiciones teóricas convergentes en que ese activismo es una extralimitación de las facultades de los jueces constitucionales, sobre todo, porque sus decisiones se inmiscuyen en políticas públicas. No obstante, esas posiciones se han sustentado en planteamientos teóricos e ideológicos, algunas de ellas provenientes de las críticas al control judicial en los Estados Unidos de América desde su génesis, así como a su posterior uso por la Corte Suprema de aquel país durante los años cincuenta y setenta.

La pretensión de este trabajo es demostrar cómo desde el diseño institucional del Estado Constitucional, el activismo judicial no puede ser comprendido como en el pasado, entre otras cuestiones, porque el activismo es una consecuencia del control judicial que se traduce en un método institucional, por consiguiente, encontrará límites racionales desde su propio diseño. De otra forma, la concretización de los fines constitucionales, no sólo se tornaría idealista, sino deficitaria en su funcionamiento, porque, en la mayoría de las ocasiones, ese activismo representará la única forma de reconocer, garantizar y concretizar derechos fundamentales.

Para desarrollar esta proposición, en primer lugar, se analizará el cómo surge el activismo judicial, pues ese génesis tendrá una repercusión teórica y práctica en su conceptualización y entendimiento en los años posteriores. Asimismo, se describirán las principales posiciones teóricas que critican al activismo judicial. En segundo lugar, se explicará la vinculación metodológica entre el control judicial y el activismo judicial, ya que esta vinculación establecerá una posición institucional de ese activismo en su sentido más primario. En tercer lugar, se analizarán las funciones que tiene en la actualidad una magistratura constitucional, las cuales no se reducen a una función de contrapeso únicamente, sino también a una función de colaboración que contribuye a un balance institucional, cuestión que obligará a un replanteamiento del activismo judicial a partir de cada una de las premisas que sustentan este trabajo. Finalmente, se concluirá que, desde el diseño institucional del régimen constitucional, el activismo judicial tiene un rol fundamental de carácter institucional en la concretización de derechos fundamentales, por tanto, los jueces constitucionales tienen una discrecionalidad proveniente de ese diseño. 


\section{2.- LAS POSICIONES TEÓRICAS DEL ACTIVISMO JUDICIAL}

El activismo judicial es uno de esos conceptos densos, ya que tiene implicaciones tanto teóricas como prácticas, no obstante, no es un objetivo desentrañar su significado, sino más bien partir de esa dualidad del concepto para develar algunas imprecisiones de gran parte de los críticos del activismo. Principalmente, porque esas críticas se han enraizado en la teoría constitucional, y si bien es claro que ese activismo se caracteriza por la indeterminación de sus límites, también es cierto que a lo largo de los años los análisis teóricos y prácticos, sobre todo, este último; representan sólo un intento por proporcionar una metodología empírica-cuantitativa para demostrar al activismo judicial en términos cualitativos ${ }^{1}$.

En este punto, es innegable la dependencia del activismo judicial con una dimensión teórica y práctica, pero, a la mayoría de esas críticas, sí se les puede situar en una posición que se sustenta sobre un asidero eminentemente teórico, sobre todo, si se atiende a las siguientes razones: 1) porque parten de una conceptualización errónea de lo que se intenta describir como activismo judicial; 2) porque al analizar el fenómeno en la práctica, se deja de lado la cuestión metodológica-institucional que lo respalda; y 3 ) porque se niega lo realista de reconocer la presencia de una ideología proveniente desde que se estableció el control judicial, la cual se entronó y se difundió a partir de los años cincuenta en Norteamérica, principalmente, por las críticas de los políticos conservadores estadounidenses hacia las prácticas de los jueces liberales que derogaban leyes estatales ${ }^{2}$.

Por lo anterior, el fenómeno del activismo judicial y sus críticas se caracterizarían de forma práctica a partir del funcionamiento de la denominada Corte Warren, pues su férreo papel en la conquista de derechos y libertades de gran importancia para la sociedad norteamericana dotaría de una ambivalencia positiva y negativa al

\footnotetext{
${ }^{1}$ Por ejemplo, los estudios de Richard Posner han sugerido que los jueces al decidir están motivados por cuestiones políticas y no sólo legales, por lo cual, ha realizado estudios cuantitativos para demostrar la frecuencia de esas motivaciones, así, para Posner, si alguna vez existió un límite a la hora de decidir, éste habría sido superado por el exuberante liberalismo activista y por la teoría constitucional norteamericana. Véase: POSNER, R., How Judges Think, Harvard University Press, EE UU, 2008, pp. 125-347. Sobre el análisis cualitativo Véase: EPSTEIN, L. y LANDEM, W., "Was There Ever Such a Thing as Judicial Self-Restraint?", California Law Review, EE UU, núm. 557, 2012, pp. 558-ss.

2 GARCÍA, L., Activismo judicial y dogmática de los márgenes de acción: una discusión en clave constitucional, Instituto de Estudios Constitucionales del Estado de Querétaro, México, 2016, p. 94.
} 
fenómeno del activismo judicial, la cual dependería de la ideología con que se observará al mismo ${ }^{3}$.

Apartándose de la tradición norteamericana, el activismo judicial tardaría en formar parte de los problemas del Estado Constitucional que surgió durante la Posguerra, pues su consolidación se caracterizaría por un proceso de constitucionalización gradual y en diferentes momentos en gran parte de los sistemas occidentales ${ }^{4}$. Este proceso tendría como eje centra la concepción de la Constitución como norma jurídica5; lo cual tendría como consecuencia reafirmar el papel de las magistraturas constitucionales que, mediante el control judicial, empezarían a resolver judicialmente asuntos que eran decididos políticamente. Precisamente, en esa convergencia tardía del activismo judicial en la cultura constitucional continental, es donde adquiere más sentido su comprensión desde una perspectiva histórica e ideológica, pues su desarrollo se ha dado a lo largo de los años y se ha nutrido, ya sea de manera positiva o negativa, de diferentes posiciones ideológicas.

Históricamente el activismo judicial iniciaría en los Estados Unidos de Norteamérica con el establecimiento del control judicial a

3 Véase: DRIVER, J., "The constitutional conservatism of Warren Court", California Law Review, EE UU, núm. 5, 2012, pp. 1101-ss. Para un análisis sobre el papel de la Corte Warren en la sociedad norteamericana. Véase: MCCLOSKEY, R., "Reflections on the Warren Court", Virginia Law Review, EE UU, núm. 7, 1965, pp. 1229-ss.

4 Sobre este proceso, el profesor Guastini refiere las siguientes condiciones de constitucionalización de un ordenamiento jurídico: 1) los derechos fundamentales incorporados a una constitución rígida; 2) la garantía jurisdiccional de la Constitución; 3) la fuerza vinculante de la Constitución; 4) la sobre interpretación del texto constitucional; 5) la aplicación directa de las normas constitucionales; 6) la interpretación adecuada de las leyes; y 7) la influencia constitucional en las relaciones políticas. Véase: GUASTINI, R., Estudios de teoría constitucional, trad. de M. Carbonell, IIJ-UNAM-Fontamara, México, 2011, pp. 153-164. Por su parte, el profesor Louis Favoreau se referirá a una constitucionalización del Derecho tomando en consideración, primero, la acumulación de normas constitucionales a través del desarrollo de la justicia constitucional $y$, posteriormente, el mecanismo de difusión de estas normas en el orden jurídico. Véase: JOSEPH FAVOREU, L., "La constitucionalización del Derecho", Revista de Derecho, núm. 1, 2001, pp. 31-43.

5 Un concepto normativo de la Constitución en la práctica judicial, se puede encontrar en la sentencia STC-80/1982 de 15 de enero de 1983, en donde el Tribunal Constitucional Español reiteró que la Constitución debía de ser entendida como una norma suprema y no como una declaración programática, pues era algo que se afirmaba de modo inequívoco y general en el artículo 9.1 del texto constitucional, donde se establece que los ciudadanos y los poderes públicos están sujetos a la Constitución; concluyéndose que esa vinculatoriedad normativa entro en vigor desde la promulgación de la misma al tener un indubitable valor como norma. 
través del paradigmático caso Marbury v. Madison de $1803^{6}$. Asimismo, el caso representó la fuente ideológica de donde parte la raíz de las críticas al activismo judicial hasta el día de hoy, ya que el caso refleja cómo surgió el cuestionamiento relativo a los límites metodológicos-institucionales en aquel tiempo ${ }^{7}$.

Así, cuando Marshall estableció el control judicial en el caso Marbury, no sólo instituyó un control material de constitucionalidad de las leyes y actos de todos los poderes, pues independientemente de colocar a la Constitución en la posición más alta posible dentro del ordenamiento jurídico y otorgar al Poder Judicial la facultad para hacer el control judicial, también se gestaron dos puntos importantes en lo relativo al activismo judicial: 1) la cuestión de que ese control se instauró y subsiste en los Estados Unidos sin estar expresamente señalado en la Constitución, sino derivado de la interpretación judicial; y 2) la oposición de Jefferson a lo decidido por Marshall, pues constituyó el sustento ideológico más fuerte para configurar las posteriores críticas al activismo judicial.

Sobre la primera cuestión, es destacable que en la actualidad prácticamente todas las constituciones contemporáneas directamente o indirectamente establecen las facultades para ejercer el control de constitucionalidad, es decir, el control judicial en la actualidad no opera $\mathrm{ni}$ se funda en una interpretación judicial, por ello, objetivamente, ese control es institucional $^{8}$. En cuanto a la segunda

6 Para un estudio profundo y desde diferentes perspectivas del caso Marbury. Véase: AMAYA, J., Marbury v. Madison: origen, argumentos y contraargumentos del control judicial de constitucionalidad, $2^{\mathrm{a}}$. ed., Ediciones Nueva Jurídica, ColombiaBogotá, 2017. Véase: MANILI, P., Marbury v. Madison: reflexiones sobre una sentencia bicentenaria, Biblioteca Porrúa de Derecho Procesal Constitucional, México, 2011. Véase: SCHOTTEN, P., "Marbury v. Madison, Rightly Understood", Perspectives on Political Science, EE UU, núm. 3, 2004, pp. 134-141.

7 Cabría mencionar que la lógica del control judicial encontraría sus raíces profundas en otro caso del Common Law, el caso The college of Physicians v. Dr. Thomas Bonham de 1610, en donde se podría hablar de un cierto activismo por parte del juez Eduard Coke, al criticar la visión que reducía al juez a un poder nulo o servil del Rey; sin embargo, no sería correcto establecer un activismo judicial en aquel tiempo, si se toma en cuenta el contexto aislado en el que se dio el caso, pues no representó el inicio de una posición sistemática de los jueces del sistema inglés. Sobre este caso y sus aportes al caso Marbury véase: REY MARTÍNEZ, F., "El Dr. Bonham 's case y su aporte a la creación de la Judicial review" en Manili, Pablo Luis (Coord.), Marbury vs Madison reflexiones sobre una sentencia bicentenaria, Editorial Porrúa-Instituto Mexicano de Derecho Procesal Constitucional, México, 2011, pp. 17-ss.

${ }^{8}$ La mayoría de las constituciones instituidas o reformadas a partir de la Posguerra establecieron un tipo de control judicial, como una forma de limitar y racionalizar al poder público y plasmándolo en los textos constitucionales de manera expresa o implícita: ya sea al señalar las facultades de los diversos órganos judiciales encargados del control judicial (concentrado o difuso); ya sea cuando los medios de 
cuestión, la posición de Jefferson en torno a lo decidido en el caso resulta crucial, porque sus críticas se centrarían en el exceso de facultades de Marshall (al final, representando a la Corte Suprema), pues desde la posición de Jefferson: 1) la judicial review violaba el mandato constitucional de separación de poderes; 2) esa revisión era una negación abiertamente de la voluntad popular expresada a través de los representantes populares; y 3 ) la Constitución no establecía un único tribunal, pero sí establecía una igualdad de todas las ramas, por lo tanto, los jueces no podían exceder sus facultades para revisar actos y leyes de los otros poderes ${ }^{9}$.

Al tener en cuenta esas objeciones y comparándolas con las objeciones actuales en torno al activismo judicial, se puede aceptar que son coincidentes en que los jueces pueden exceder sus facultades al realizar su función, lo cual devendría en una extralimitación de su poder frente a los otros poderes públicos y, por tanto, su función se torna activista. Consecuentemente, es plausible afirmar que el activismo judicial surge con el caso Marbury, porque es claro que el propio establecimiento del control judicial implicó un activismo por parte de Marshall, no sólo por exceder sus facultades, más bien por no existir tales atribuciones en la Constitución norteamericana.

Cuestión que resulta más que importante para este trabajo, pues las críticas contemporáneas al activismo judicial parten de ese exceso de facultades, pero, a diferencia de la actualidad, las objeciones de Jefferson a la actitud de Marshall en aquel tiempo eran justificadas. Por ello, las críticas modernas no se pueden sostener de la misma forma como se verá más adelante, sobre todo, porque algunas constituciones prevén disposiciones expresas para la revisión judicial de la constitucionalidad de las leyes y, en estos casos, la legitimidad institucional de esa revisión no debería de ponerse en duda ${ }^{10}$.

Por todo lo señalado, resulta pertinente centrarse en tres de las principales posiciones teóricas en torno al activismo judicial. Por una parte, desde una contraposición al formalismo, como señala el profesor Atienza, el activismo y el formalismo podrían considerarse como el Escila y el Caribdis que deben evitar los jueces, es decir, que los jueces tienen la obligación de utilizar únicamente razones

control judicial de constitucionalidad refieren cuál es el órgano competente para conocer, substanciar y resolver algún proceso de control judicial.

${ }^{9}$ Cfr. WARREN, C., "The Story Marshall Correspondence (1819-1831)", The William and Mary Quarterly Historical Magazine, núm.1, enero de 1941, pp. 1-ss.

10 Cfr. BARAK, A., Un juez reflexiona sobre su labor: el papel de un tribunal constitucional en una democracia, trad. de E. Vela Barba, Suprema Corte de Justicia de la Nación, México, 2008, p. 31. 
jurídicas, pero que la vinculación de los jueces no es solo al tenor de las normas ${ }^{11}$.

Por otra parte, desde una posición política, en este caso, se hace referencia a la intervención de los jueces en política y políticas públicas $y$, por consiguiente, a una extralimitación de sus facultades que no respetan a los otros poderes; ya que en la actualidad las magistraturas constitucionales participan de las decisiones políticas ${ }^{12}$. Finalmente, desde una posición interpretativa, como lo describe el profesor Guastini, que define al activismo judicial como una interpretación dinámica que se inspira, ya sea en el valor de la congruencia del Derecho con la conciencia social; ya sea en una meta-ética utilitarista; ya sea en el deber constitucional de los jueces de proteger los derechos de los ciudadanos y de las minorías en contra de las mayorías políticas ${ }^{13}$.

A pesar de las diferentes visiones de esas posiciones y tomando en cuenta la extensión de este trabajo, se establecerá una convergencia de las mismas y una delimitación al considerar que, el activismo judicial, se caracterizará tanto en un papel protagónico de la jurisdicción constitucional, como en una extralimitación de las facultades del juez constitucional ${ }^{14}$. Consecuentemente, el razonamiento analítico partirá de la explicación de los siguientes puntos: 1) porqué se habla de un papel protagónico de la jurisdicción constitucional, en este caso, el trabajo se referirá a la injerencia del control judicial en política y políticas públicas; 2) cuáles son esos límites que exceden los jueces constitucionales, sobre esto, el trabajo se refiere a los límites constitucionales; y 3) cómo es que se pueden exceder esos límites, justamente, en este último punto, el trabajo colocará y desarrollará las críticas al activismo judicial.

11 Cfr. ATIENZA, M., Curso de argumentación jurídica, Editorial Trotta, España, 2016, p. 51.

12 Cfr. FIX ZAMUDIO, H., "La legitimación democrática del juez constitucional", en E. FerRer y C. Molina (coords.), El juez constitucional en el siglo XXI, UNAM-SCJN, 2009, México, t. I, p. 159.

${ }^{13}$ Cfr. GUASTINI, R., Teoría e ideología de la interpretación constitucional, 2a. ed., trad. de M. Carbonell y P. Salazar, IIJ-UNAM-Editorial Trotta, México, 2010, p. 64.

14 Esta convergencia y delimitación admite matices, pues el propio concepto de activismo judicial entrañará diferentes interpretaciones dependiendo de las posiciones que se defiendan, por ejemplo: para un originalista o textualista, el activismo judicial se podría dar con el sólo hecho de que un juez constitucional interprete de forma extensiva un precepto constitucional; o el denominado formalismo judicial que ve a un juez constreñido a la legalidad, es decir, prioriza las razones formales. Véase: AGUILÓ REGLA, J., "En defensa del estado constitucional de derecho", Doxa Cuadernos de Filosofía del Derecho, España, núm. 42, 2019, pp. 96-99. 


\section{3.- EL CONTROL JUDICIAL DE CONSTITUCIONALIDAD Y EL ACTIVISMO JUDICIAL}

Ya se había mencionado una vinculación del activismo judicial con el control judicial derivado de su génesis, no obstante, es conveniente establecer una primer premisa, la cual se fundamenta en que existe una vinculación institucional y estructural entre ambos a partir de las siguientes razones: 1) porque el control judicial presupone al activismo judicial, es decir, gran parte del desenvolvimiento del control judicial se expresa a través del activismo judicial y, a su vez, sin control judicial no se podría hablar de un activismo judicial; y 2) porque el control judicial siempre tenderá a interferir institucionalmente con los poderes y órganos estatales, pues los jueces constitucionales pueden y deben invalidar cualquier acto de los otros poderes cuando sea contrario a la Constitución.

Consecuentemente, la premisa establecida coloca al activismo judicial en una dimensión exclusivamente constitucional, por ello, al hablarse de límites en realidad se hace referencia a los límites constitucionales de los jueces, porque de manera congruente y pacífica se puede reconocer que es la Constitución la que permite y mandata ejercer el control de constitucionalidad. Cuestión que se traduce en una obligación constitucional a cargo del juez constitucional de revisar todos los actos de los poderes y órganos estatales que, de alguna manera, interferirá (si se quiere utilizar ese término) con las funciones y tareas de esos poderes y órganos, sin importar si son de naturaleza política o jurídica.

Todo lo anterior establecerá una segunda premisa, la cual se refiere a la función del juez constitucional y los fines constitucionales en abstracto y específico. Los fines en abstracto, se referirán a la protección y realización de los derechos fundamentales, la construcción de la sociedad democrática y la adaptación de la Constitución a la realidad social; en estos fines se puede observar una compleja finalidad a conseguir por el juez constitucional, es decir, cerrar la brecha entre el Derecho y la Sociedad ${ }^{15}$.

Por su parte, los fines en específico, se relacionarán con la materialización del contenido constitucional, en donde el juzgador constitucional deberá de centrarse en las tareas de reconocimiento, garantía y concretización del contenido constitucional, sobre todo, los

15 Cfr. BARAK, A., Un juez reflexiona sobre su labor: el papel de un tribunal constitucional en una democracia, cit., p. 2. 
derechos fundamentales ${ }^{16}$; porque en la actualidad estos derechos también son de carácter prestacional ${ }^{17}$.

Ambos fines son de suma importancia, pues las necesidades de cambios constitucionales representan un dilema complejo al juzgador constitucional, porque implica dañar la seguridad jurídica, la certeza y la estabilidad, así, el juzgador tendrá a su cargo equilibrar la necesidad del cambio y la necesidad de estabilidad ${ }^{18}$, en otras palabras, la función del juez constitucional contribuye a reducir esa brecha sin permitir que el sistema jurídico se degenere o se colapse en una anarquía ${ }^{19}$.

Justamente, en ese punto, las posiciones que critican al activismo judicial centran sus baterías en que el juez constitucional es discrecional, pues en la consecución de esas tareas y fines, así como para reducir esa brecha entre el Derecho y la sociedad; hará uso de decisiones arbitrarias ${ }^{20}$. Lo cual es un error si se toma en cuenta que una decisión será arbitraria, sólo cuando no encuentra fundamentación en argumento racional, cuestión que lleva a confundir la arbitrariedad con la discrecionalidad ${ }^{21 .}$

\footnotetext{
16 Desde la perspectiva de este trabajo, estas tareas son primarias de las funciones generales que se realizan en una magistratura constitucional, pues, en conjunto, representan una metodología para concretizar los derechos fundamentales. Primero, la tarea de reconocimiento, se referirá a cómo se le da un contenido a los derechos humanos que han sido positivizados en el sistema o, inclusive, la creación de derechos derivados de otros derechos fundamentales o principios constitucionales. Segundo, la tarea de garantía, que se realiza cuando la magistratura declara que un derecho fundamental debe de ser garantizado por el Estado en abstracto o, en concreto, por un órgano, poder u agente social, en otras palabras, se constituye una prerrogativa concreta para una persona o grupo de personas en la sentencia. Tercero, la tarea de concretización, que se entiende cómo la materialización de los derechos fundamentales en la realidad social, lo cual implicará una supervisión de cumplimiento de la sentencia por parte de la magistratura hasta que ese objetivo sea efectivamente cumplido en la realidad.

17 En otras palabras, un principio de plenitud deóntica en virtud del cual donde quiera que existan derechos, existirá una prohibición de lesionarlos y la obligación de tutelarlos y satisfacerlos. Véase: LUIGI, F., La democracia a través de los derechos. El constitucionalismo garantista como modelo teórico y como proyecto político, trad. de P. A. Ibáñez, Editorial Trotta, Madrid, 2014, p. 58.

18 Cfr. BARAK, A., Un juez reflexiona sobre su labor: el papel de un tribunal constitucional en una democracia, cit., p. 3.

${ }^{19}$ Cfr. Ibid., p. 4.

${ }^{20}$ La arbitrariedad puede ser entendida como la decisión sin sujeción a una norma jurídica, por ende, contraria al Derecho. Un ejemplo puede ser encontrado en el artículo 9.3 de la Constitución Española, cuando establece que la norma fundamental garantiza la interdicción de la arbitrariedad de los poderes públicos. Véase: GARCÍA DE ENTERRÍA, E. y MENÉNDEZ, A., El Derecho, la ley y el juez. Dos estudios, Editorial Civitas, España-Madrid, 1997, pp. 80-83.

${ }^{21}$ Cfr. OSSA HENAO, M., La discrecionalidad judicial, Leyer Editores, Bogotá, 2015, pp. 25-26.
} 
Pues la discrecionalidad en la decisión judicial, en un sentido general, no puede ser otra que la que se sustenta en la prudencia y la razonabilidad, en consecuencia, no puede ser contraria a los principios constitucionales y derechos fundamentales ${ }^{22}$. Esta cuestión resulta más compatible con uno de los presupuestos del Estado Constitucional, ya que el Derecho ha pasado de ser aplicado por autoridad a ser aplicado mediante razones. De esta forma, toda decisión de los jueces deberá de ser motivada o, mejor aún, argumentada para la solución razonable del conflicto, por tanto, la discrecionalidad motivada no se apartaría de la discrecionalidad en general23.

En este punto, los únicos límites que podría exceder la discrecionalidad de los jueces constitucionales se refiere a dos direcciones posibles. La primera, fuera de los propios límites constitucionales, esto es, que realmente no se encuentren en un verdadero Estado Constitucional o exista un serio déficit en él, porque sólo así podrían ir más allá de lo que el propio texto les permite. Y, la segunda, que las decisiones tomadas respeten los límites constitucionales, pero que el proceso de decisión no respete la certeza, la seguridad jurídica y la estabilidad que es exigible a la toma de decisiones colectivas fundamentales ${ }^{24}$.

22 Cfr. Ibid., p. 33.

${ }^{23}$ Cfr. Ibid., p. 37.

24 En ese sentido, estos dos puntos ejemplifican la diferencia entre discrecionalidad y arbitrariedad, lo cual no significará que esa diferencia sea del todo clara y, más aún, que el activismo judicial no pueda ser criticado desde el ámbito de la discrecionalidad, pues existirán casos en donde un juez constitucional tome una decisión dentro de su potestad discrecional, pero, el resultado de esa decisión, sea criticado como activismo judicial dependiendo de la posición y el contexto de esas críticas. Un ejemplo de esta cuestión, desde la práctica judicial constitucional, se puede observar en la sentencia 0084/2017 del Tribunal Constitucional Plurinacional boliviano, porque la decisión podría ser vista desde un margen de discrecionalidad en estricto sentido, pero, al mismo tiempo, también bajo un margen de arbitrariedad, porque la Sala Plena del Tribunal realizó un control de convencionalidad a la propia Constitución boliviana, lo cual fue duramente criticado por permitir la reelección presidencial en aquel país, bajo el argumento de que la prohibición constitucional de reelección estaba en contra de los estándares interamericanos de derechos humanos, en un caso similar, la Suprema Corte de Justicia de la Nación mexicana, en la contradicción de tesis 293/2011, fue duramente criticada por cerrar la posibilidad de realizar un control de convencionalidad a la Constitución mexicana, concretamente, disuadió la posibilidad de declarar la inconvencionalidad de la figura del arraigo que, en el sistema mexicano, es constitucional, pero, bajo los estándares interamericanos, sería inconvencional. En ambos casos, existió una discrecionalidad que permitió a esas magistraturas constitucionales determinar en cada caso la permisión o prohibición del control de convencionalidad, en ese sentido, el determinar si existió un activismo judicial dependerá del contexto y la posición que se defienda en cada caso. 
Consecuentemente, la legitimación de la discrecionalidad se haya íntimamente relacionada con sus límites, pues creer que esa discrecionalidad es libertad absoluta de apreciación o decisión, es no comprender la distancia que la separa de la arbitrariedad ${ }^{25}$. En consonancia, las constituciones contemporáneas imponen como límite ineludible para el juez constitucional, la naturaleza del Estado Constitucional de Derecho, cuyo fundamento se encuentra en esa vigencia y prevalencia de los derechos fundamentales $y$, en general, siempre existirá la exigencia de un fin constitucional legítimo que en ningún caso podrá ser desconocido ${ }^{26}$.

En todo caso, podría objetarse a los críticos del activismo que los jueces constitucionales, independientemente de los límites constitucionales ${ }^{27}$, también consideran: 1) la coherencia del sistema en el que operan cuando toman sus decisiones; 2) los poderes y limitaciones de la institución en la que operan, es decir, la particularidad y posición de ese órgano dentro del sistema jurídico; y 3) la forma en que se percibe su función en la sociedad e institucionalmente ${ }^{28}$. Asimismo, resulta importante señalar que en las jurisdicciones constitucionales opera el sistema de precedente 0 jurisprudencia que, en gran medida, orienta y constriñe las decisiones de los juzgadores constitucionales, porque apartarse de un precedente o la jurisprudencia debe de ser la excepción, no la regla; pues el juez deberá de ser explícito y asumir responsabilidad personal de ese cambio 29 .

Paralelamente, hacia el interior de las magistraturas constitucionales existen otros límites que no están determinados en la Constitución, sino que se dan intra-institucionalmente, porque un juez constitucional con el paso de los años crea un sistema propio que refleja su política judicial ${ }^{30}$. La cual, en gran medida, es respetada y considerada por los integrantes de una magistratura, sobre todo, para dar coherencia a lo decidido en conjunto (Per Curiam), así como credibilidad frente a la sociedad, poderes y órganos públicos. Por todas esas condiciones, la supuesta

\footnotetext{
${ }^{25}$ Cfr. OSSA HENAO, M., La discrecionalidad judicial, cit., p. 45.

${ }^{26}$ Cfr. Ibid., p. 47

27 Por ejemplo, el método de interpretación conforme a la Constitución representa otro límite, pues en general y dependiendo del sistema de que se trate, al final puede limitar a todos los jueces de un sistema jurídico; incluidos los jueces constitucionales. Véase: KLATT, M., Hacer el Derecho explícito. Normatividad semántica en la argumentación jurídica, trad. de F. J. Campos Zamora, Marcial Pons, Madrid-España, 2017, p. 26.

28 Cfr. BARAK, A., Un juez reflexiona sobre su labor: el papel de un tribunal constitucional en una democracia, cit., p. 4.

${ }^{29}$ Cfr. Ibid., p. 6.

${ }^{30}$ Cfr. Ibid., p.7.
} 
arbitrariedad que se confunde con la discrecionalidad del juez constitucional, es parte integral de las críticas del activismo judicial, no obstante, esas críticas no resultan precisas cuando se refieren a los límites que excede el activismo judicial, sino más bien se sitúan en suposiciones de cómo podría degenerar esa discrecionalidad en arbitrariedad.

En este punto se puede introducir una variable más a la cuestión de los límites, donde se abordará lo concerniente al efecto de las sentencias constitucionales en política y políticas públicas, así, se establecerá una tercera premisa sustentada en que una decisión en sede constitucional, principalmente de última instancia, tendrá una interferencia y significado político en un sentido amplio dentro de un sistema jurídico. Porque una de las principales objeciones tanto para el control judicial como para el activismo judicial, es la pretensión escéptica de que las magistraturas constitucionales no producen o sería deseable que no produjeran decisiones políticas o, en general, que no se inmiscuyeran en política. Objeción que se sustenta, mayormente, en que una magistratura constitucional es un órgano estatal carente de legitimidad democrática, por lo cual no tiene la autoridad para poder anular una política pública emanada de un órgano con legitimidad democrática, como el de los poderes Ejecutivo - Legislativo ${ }^{31}$. Asimismo, se identificará a la magistratura constitucional como un órgano que, al no emanar del voto popular, es apolítico y permanecerá siempre inmune a la política y sus decisiones ${ }^{32}$; en otras palabras, esa objeción podría admitir el control judicial en cuestiones estrictamente jurídicas, pero no aceptaría la justiciabilidad de las cuestiones políticas (political question doctrine) $)^{33}$.

\footnotetext{
${ }^{31}$ Sobre el tema de la legitimidad democrática del juez constitucional, no se puede desarrollar una respuesta completa y satisfactoria en este trabajo, por ser un fenómeno tan vasto y complejo del derecho y la teoría constitucionales; sin embargo, para el planteamiento que se pretende sobre las críticas al activismo judicial, no será necesario profundizar en ese tema como tal, porque las críticas a la legitimidad democrática del juez constitucional refutaran al control judicial sin importar que exista o no un activismo judicial.

32 Por ejemplo, esta visión y su contraposición se puede ver en los célebres debates entre Kelsen y Schmitt, en donde ambos sostuvieron posturas contrarias en torno a quién debería de ser el defensor de la Constitución, pues Schmitt afirmaba que, si un tribunal constitucional revisara la constitucionalidad de las leyes, se produciría una politización de la justicia; mientras que Kelsen pugnaba por una judicialización de la política. Véase: HERRERA, C. M., "La polémica Schmitt-Kelsen sobre el guardián de la Constitución", Revista de Estudios Políticos, España, núm. 86, 1994, pp. 209-ss.

33 Este término proviene de la doctrina norteamericana que afirma una obligación de autolimitación (self restraint) de los jueces, la cual les impide conocer y resolver dentro del proceso judicial cuestiones políticas. Sobre este tema véanse: HENKIN,
} 
Sobre todo, porque se cree firmemente en que las cuestiones políticas no pueden resolverse sobre la base de argumentos jurídicos, pues estas cuestiones entrañan decisiones de carácter valorativo y moral que, en sede judicial, se reducen a argumentos puramente lógicos o formales. Lo cual resultaría una visión incompleta, porque no toma en cuenta: 1) la función de una magistratura constitucional en la actualidad, en donde las decisiones se dan bajo un orden objetivo de valores contenido en la Constitución y, el Derecho, inevitablemente tiene una dimensión de moralidad que subyace al derecho legislado ${ }^{34}$; y 2) no se distingue entre el proceso de toma de decisiones de la magistratura y el resultado de esas decisiones, porque el resultado de una decisión en esa sede constitucional, la mayoría de las ocasiones tendrá un efecto directo o indirecto con política y políticas públicas.

Bajo esas condiciones, las críticas al activismo judicial sobre ese tema se reducen a argumentar que, cuando las decisiones de una magistratura constitucional se inmiscuyen en política o políticas públicas, los jueces constitucionales están siendo activistas al invadir la esfera política que es propia de los poderes Ejecutivo y Legislativo; no obstante, ese argumento no toma en cuenta las siguientes condiciones.

Primero, porque es innegable que durante muchos años se sitúo a la Constitución como objeto de estudio de la teoría política, sobre todo, por su carácter político, lo cual llevo a establecer que el derecho constitucional, por referirse propiamente al ámbito del Estado, tenía un carácter mayormente político. Esta aseveración en parte es verdadera, pero, en la actualidad, resulta falsa porque uno de los postulados del constitucionalismo contemporáneo establece que todos los ámbitos en el Estado están constitucionalizados, es decir, el ámbito político, público y social se someten al contenido constitucional. De esta forma, la naturaleza jurídica de la Constitución irradia también a la política, porque los problemas de índole político también se solucionan de manera institucional bajo reglas y principios constitucionales.

Segundo, porque es difícil negar o refutar la afirmación de que todo proceso político está o debe de estar determinado por la Constitución, pues sólo así se daría sentido al Estado Constitucional, ya que de otra manera se estaría aceptando que la política se posiciona u opera por encima del texto constitucional. Lo cual resulta

L., "Is there a political question doctrine?", The Yale Law Journal, EE UU, vol. 85, núm. 5, 1976, pp. 597-625; así como TUSHNET, M., "Law and prudence in the law of justiciability: The transformation and disappearance of the political question doctrine", North Carolina Law Review, EE UU, vol. 80, 2002, pp. 1203-1235.

34 Cfr. OSSA HENAO, M., La discrecionalidad judicial, cit., p. 39. 
inexacto, ya que tanto la política como sus procesos deben de estar fundados y regularse constitucionalmente, sobre todo, porque si bien el gobierno del pueblo implica una supremacía legislativa, inclusive bajo el esquema de mayorías políticas, esta visión resulta incompleta, porque la supremacía no pertenece a ningún poder u órgano del Estado, sino al texto constitucional ${ }^{35}$.

Tercero, porque el texto constitucional goza de una fuerza normativa en oposición al carácter político que se le dio en los años anteriores a la Posguerra, pues debe de admitirse que, gran parte de la justicia o jurisdicción constitucional, se da a través de un proceso eminentemente judicial (revisión judicial); sin embargo, el resultado de ese proceso, en menor o mayor grado, siempre tendrá en general consecuencias políticas 0 , en específico, se inmiscuirá en políticas públicas, sobre todo, cuando precisamente las condiciones políticas o del gobierno no se ajustan a la Constitución.

Cuestión que se sitúa dentro de una esfera institucional, porque la interferencia en política o políticas públicas no se da de manera deliberada, por el contrario, cuando las leyes son invalidadas mediante el control judicial, en esos casos, la ley que fue diseñada por la legislatura para efectuar una política pública en nombre de sus electores, es tomada en cuenta y se le da expresión a esa interpretación del legislador ${ }^{36}$; pues el juez constitucional en su análisis toma en cuenta la deferencia al legislador y la presunción de constitucionalidad de las leyes.

Por ello, si se toma en cuenta que por política se entiende a los procesos políticos para la toma de decisiones por una entidad colectiva, para regular su orden interno y las relaciones de conflicto, de concurrencia y de cooperación entre las personas y grupos que influyen en las decisiones colectivas ${ }^{37} ; \mathrm{y}$, por políticas públicas, a todo aquel resultado del ejercicio del poder público de los órganos y poderes estatales ${ }^{38}$.

Bajo esas definiciones, el control judicial de las leyes y actos se perfila como un mecanismo al menos útil para mantener al proceso político dentro de los límites trazados por los presupuestos sustantivos y adjetivos de la democracia, generalmente constitucionalizados; en otras palabras, ese control representa una

35 Cfr. BARAK, A., Un juez reflexiona sobre su labor: el papel de un tribunal constitucional en una democracia, cit., pp. 18-20.

${ }^{36}$ Cfr. Ibid, p. 20.

37 GARCÍA, M., "El status del Tribunal Constitucional", Revista Española de Derecho Constitucional, núm. 1, 1981, p. 22.

38 GONZÁLEZ, B., "El concepto de política pública en la administración pública norteamericana", Revista de Administración Pública. Escuela Graduada de Administración Pública, s.n. pp. 60-ss. 
opción válida de diseño institucional ${ }^{39}$. Consecuentemente, el control judicial tendrá consecuencias políticas: ya sea porque invalida políticas públicas; ya sea porque produce consecuencias políticas; o, inclusive, porque la misma tensión con la democracia impactará en lo político. No obstante, algo que debe quedar muy claro es que, el control judicial, no es un proceso político ni se lleva a cabo por un órgano político, sino que atiende a un modelo institucional que tiene consecuencias políticas.

En resumen, la mayoría de las críticas al activismo judicial pretenden establecer como política la actuación de la magistratura y los jueces constitucionales, ello, a partir de: 1) por los temas que regula el texto constitucional, los cuales son sociales, públicos, privados y políticos; y 2) porque los jueces constitucionales invalidan decisiones políticas fundamentales, es decir, leyes, reglamentos $u$ actos de los poderes y órganos estatales. Al final, ambos supuestos resultan erróneos porque la Constitución es una norma jurídica por su interpretación y aplicación, no así por su contenido, por tanto, las magistraturas constitucionales producirán decisiones políticas, aunque su proceso de decisión no se realiza políticamente; cuestión que es totalmente diferente de señalar que los jueces constitucionales deciden políticamente y hacen política.

Al tener clara esta distinción, se puede establecer una cuarta premisa, la cual se relaciona con una cuestión que pasa desapercibida para la mayoría de las críticas al activismo judicial; y es que los jueces activistas en realidad son activistas condicionados. Es decir, para que el activismo judicial se produzca, es necesario que los casos sean llevados a la magistratura constitucional, porque los jueces no son autogeneradores de controversias o casos, sino que ellos crean Derecho esporádicamente 40 .

Por tanto, esta premisa se basará en la forma en que los casos llegan a una magistratura constitucional, ya que sólo pueden ser llevados por una persona, por un grupo de personas o por un poder $u$ órgano estatal. Lo cual inhibe en gran mediad la arbitrariedad de los jueces para posicionarse política o ideológicamente, pues bajo esa premisa, en sentido estricto el activismo judicial proviene desde tres fuentes: 1) de la dinámica social, a través de diferentes agentes sociales que en algunos aspectos no coinciden con la política o ideología imperante; 2) de la oposición política, la cual mediante mecanismos institucionales hace valer ese carácter; y 3) de los

39 Cfr. CASAL, J., Las transformaciones del constitucionalismo y la justicia constitucional, Editorial Porrúa-IMDPC, México, 2017, p. 120.

40 Sobre este punto, los jueces constitucionales hacen cambios parciales, limitados y reactivos a las leyes. Véase: BARAK, A., Un juez reflexiona sobre su labor: el papel de un tribunal constitucional en una democracia, cit., p. 8. 
propios poderes y órganos estatales, los cuales buscan resguardar el orden constitucional.

\section{4.- UN REPLANTEAMIENTO DEL ACTIVISMO JUDICIAL}

En el apartado anterior se han establecido cuatro premisas que sirven como base para replantear el activismo judicial: 1) la vinculación estructural e institucional del activismo judicial con el control constitucional, por lo cual, el activismo se desarrolla institucionalmente dentro de los límites constitucionales; 2) los fines del control constitucional al igual que del activismo judicial son la garantía de los derechos fundamentales, la realización de la sociedad democrática y la adaptación del texto constitucional a la realidad; 3 ) las decisiones que se toman en una magistratura constitucional tienen un significado político y se inmiscuyen en políticas públicas, ello, a causa de la constitucionalización de la política; y 4) los jueces constitucionales, para ser activistas, están condicionados a que los casos sean provistos por los agentes sociales, la oposición política o los poderes y órganos estatales.

Asimismo, resulta pertinente tener en cuenta lo apuntado sobre la ideología proveniente del caso Marbury $v$. Madison, en donde también surgieron las primeras críticas al papel de los jueces por exceder sus funciones e inmiscuirse en política, pues las condiciones de esa ideología y críticas en el Estado Constitucional actual, no pueden ser entendidas de la misma forma que en aquella época. Principalmente, porque el control judicial en Norteamérica surgió sin un sustento constitucional claro y, en ese tiempo, no se tenía una dimensión sobre la importancia que tendría la Corte Suprema para el sistema jurídico, cuestión que se reflejaría en los años posteriores, cuando la Corte legitimara su importante rol institucional en el sistema y la sociedad norteamericana a través de su activismo judicial.

Por lo anterior, en el Estado Constitucional contemporáneo la perspectiva cambia, ya que los derechos fundamentales son el cimiento del Estado, lo cual condiciona a las mayorías democráticas, la ideología y la política, porque todas estas deberán de respetar y estar de acuerdo con esos derechos. Así, los jueces constitucionales cumplen con una importante función de protección-límite de los derechos constitucionales mediante el control constitucional, pues tanto la necesidad del Estado como de los derechos fundamentales es parte de una estructura constitucional que, simultáneamente, trabaja 
a favor de esos derechos, pero los limita también a la vez que preserva el marco sociopolítico ${ }^{41}$.

En este punto, los límites al control judicial son la seguridad jurídica, la certeza y la estabilidad del sistema, los cuales regularmente son respetados por los juzgadores constitucionales, porque en sede constitucional de última instancia, el proceso de decisión es orientado a un fin constitucional: ya sea por la Constitución; ya sea por la jurisprudencia o el precedente; ya sea por la política judicial de la magistratura; ya sea por los efectos de sus sentencias. Al final, el propósito de interpretar el texto constitucional por parte de los jueces constitucionales, es cumplir con la finalidad para la cual ese texto fue diseñado, interpretación que tendrá un significado jurídico de acuerdo al rango de los diversos significados semánticos de la propia Constitución; lo cual reducirá significados que su lenguaje explícito o implícito no pueda sostener ${ }^{42}$.

De esta forma, es posible establecer una bifurcación de dos posiciones en torno al activismo judicial. La primera, que puede entenderse desde una perspectiva positiva, en donde los jueces constitucionales utilizan la Constitución como un medio para cerrar la brecha entre la sociedad y el Derecho, así como potenciar e, inclusive, crear o reconocer nuevos derechos a las personas y grupos sociales, pero, siempre de forma institucional y respetando sus facultades constitucionales.

La segunda, que puede comprenderse desde una perspectiva negativa, en donde los juzgadores constitucionales asumen un papel protagónico con fines abiertamente estratégicos, ideológicos y políticos mediante un alejamiento y uso arbitrario de sus facultades y atribuciones constitucionales. Sobre esta última perspectiva, es difícil encontrar en la práctica judicial que los jueces constitucionales tengan esas posturas tan abiertamente explicitas y claras, más bien representa una posición teórica y sin sustento empírico que ve a los jueces constitucionales como activistas porque: 1 ) reconocen y crean derechos fundamentales, los cuales no se encuentran expresamente en la Constitución; o 2) sus decisiones tienen un significado político o repercuten en políticas públicas. En ambos casos tendría que refutarse no sólo al activismo judicial, sino también al control judicial $y$, por consiguiente, al diseño institucional del Estado Constitucional y sus finalidades.

Por ello, el activismo judicial es más compatible con ese diseño constitucional si se analiza desde la perspectiva positiva, pues representará una expresión del importante rol institucional de una

41 Cfr. BARAK, A., Un juez reflexiona sobre su labor: el papel de un tribunal constitucional en una democracia, cit., pp. 24-25.

${ }^{42}$ Cfr. Ibid., pp. 58-61. 
magistratura constitucional, el cual no sólo se reducirá a una función de contrapeso frente a los poderes Legislativo y Ejecutivo, sino también representará una significativa función de colaboración para lograr un balance institucional entre poderes y órganos estatales compatible con una sociedad democrática ${ }^{43}$.

En todo caso, si se observa al activismo desde una perspectiva funcional y estructural de diseño constitucional, los poderes Legislativo y Ejecutivo podrían ser más activistas que una magistratura constitucional, pues son varias las ocasiones en que una ley o política pública se crea, impulsa y promulga bajo intereses políticos o estratégicos, inclusive, en contra de derechos y principios constitucionales. Cuestión que, si bien atiende a la naturaleza política de esos poderes públicos, también es cierto que puede tornarse activista al posicionar ideologías de diversa índole, pues sus límites desde el diseño institucional no pueden evitar posiciones estratégicas y políticas, sino que esos límites se establecerán desde una perspectiva de corrección; es decir, sería deseable que una ley o política pública se encuentre ajena a esas posiciones.

De esta manera, al criticarse el activismo judicial porque invalida leyes y políticas públicas, en ese caso, primero debería de tomarse en cuenta un posicionamiento ideológico, político y estratégico de las propias leyes y políticas públicas, porque los jueces activistas no se reúnen en la magistratura y deliberan en torno a qué ley o política pública les parece bien o mal, sino que esperan a que desde la sociedad o los propios poderes y órganos estatales, les alleguen los casos que serán revisados sobre una base constitucional y no ideológica o política.

Por ejemplo, cuando en los años setenta en los Estados Unidos se tachó a los jueces de activistas por reconocer un derecho constitucional a abortar a las mujeres, realmente tendría que haberse analizado el espectro que rodeaba al fenómeno, es decir, se debió de tomar en cuenta: 1) las legislaciones y su posicionamiento político e ideológico respecto del aborto; 2) la fuente social del reclamo hacia el derecho a abortar; y 3) que esos justices activistas de la Suprema Corte centraron su análisis a decidir sobre si encontraban un sustento

43 Un ejemplo paradigmático de esa colaboración se puede encontrar en las llamadas sentencias dialógicas, en donde la Corte Constitucional Colombiana no sólo se desempeña como un órgano de contrapeso, sino que, para la realización de los derechos fundamentales, involucra y supervisa la intervención de otros poderes y órganos del Estado con la finalidad de lograr un pleno goce de los mismos; cuestión que puede ser observada en las sentencias $T-398 / 2019, T-2010 / 2018$ y $T$ 622/2016, entre otras. Sobre este tema véase también: OSUNA, N., "Las sentencias estructurales", en Bazán, Víctor, (ed.), Justicia constitucional y derechos fundamentales No 5. La protección de los derechos sociales. Las sentencias estructurales, Konrad Adenauer Stiftung, Colombia, 2015, pp. 89-125. 
constitucional, derivado del derecho fundamental a la right to privacity, para que las mujeres pudieran abortar sin ser penalizadas.

La cuestión a resaltar de este ejemplo, es que el activismo judicial caracteriza institucionalmente una exigencia desde la sociedad, ello, para adaptar el Derecho a la realidad social, pues los jueces constitucionales, más que realizar activismo, cumplen con una obligación de reflejar el pluralismo social de la mejor manera posible dentro de los cauces institucionales y, en la mayoría de las ocasiones, para poder concretizar los derechos fundamentales. De otra forma, esos derechos estarían condicionados a posiciones estratégicas, ideológicas y políticas tanto de generaciones pasadas como de las mayorías actuales o, en el peor escenario, se buscaría la concretización de esos derechos por vías no institucionales.

Así, los límites al activismo judicial están enmarcados en: 1) por las atribuciones y facultades para ejercer el control constitucional, las cuales se encuentran en el texto constitucional, así como por la política judicial y los efectos de las sentencias que se producen en la magistratura constitucional; 2) el parámetro objetivo que representan los derechos fundamentales, porque los jueces constitucionales al decidir los casos, principalmente se fundaran sobre esa base interpretativa; y 3 ) el respeto a la sociedad democrática, pues sus decisiones de una u otra manera tenderán a fortalecer el régimen democrático, esto es, ya sea que declaren inconstitucional la ley o política pública, entonces, se hablará de que se garantizó el respeto a las minorías frente a las mayorías $o$, en el extremo contrario, al declarar la constitucionalidad de esa ley o política, en ese caso, se dirá que se respetó el valor del autogobierno y las mayorías democráticas.

\section{5.- A MODO DE CONCLUSIÓN}

La intención de este trabajo era brindar una visión más realista del activismo judicial, en donde este fenómeno sea visto a la luz del significado del Estado Constitucional, pues desde su diseño institucional, ese activismo, como una consecuencia del control judicial, representa una forma realista de concretizar el contenido constitucional, porque esa nueva concepción, al mismo tiempo, enarbola una visión crítica y constructiva acerca de las posibilidades del Derecho en la realidad.

Dentro de esas posibilidades, resulta necesario aceptar el papel fundamental de los jueces constitucionales, el cual no sólo se limita a una función de contrapeso, sino también a una función de colaboración para lograr un balance institucional que, al final, tendrá como único objetivo la concretización de los derechos fundamentales. 
Así, el activismo judicial exige del juzgador constitucional un rol creativo, interviniente y teleológicamente orientado por: 1) el plexo de valores contenido en las normas constitucionales; 2) los valores básicos consagrados en cada ordenamiento jurídico; y 3) por los efectos sociales de su aplicación ${ }^{44}$.

Asimismo, el activismo judicial se aleja de la arbitrariedad que se confunde con la discrecionalidad, pues esta última se encuentra institucionalmente limitada por; 1 ) las facultades constitucionales que permiten el control judicial; 2) la congruencia del sistema de precedente o jurisprudencia del sistema jurídico; 3 ) la política judicial de la magistratura constitucional; y 4) los parámetros interpretativos que representan los derechos y principios constitucionales.

Finalmente, el activismo judicial debe de entenderse como uno de los medios institucionales para dar cauce a las demandas sociales, lo que ayuda a recrear de la mejor forma posible el pluralismo social, porque para lograr la realización de la sociedad democrática también es necesario garantizar los derechos de las minorías, inclusive, frente a las mayorías democráticas ${ }^{45}$. Consecuentemente, las críticas en contra del activismo pierden fuerza al basarse en posiciones teóricas sin ningún sustento empírico que pueda observarse en la práctica judicial, pues sólo se refieren a una posición hipotética de una supremacía de los jueces constitucionales a través del activismo judicial, olvidándose que esa posición se les ha otorgado constitucionalmente, porque en una democracia constitucional ningún poder es supremo; sólo la Constitución es suprema ${ }^{46}$.

\section{6.- BIBLIOGRAFÍA}

AGUILÓ REGLA, Josep, "En defensa del estado constitucional de derecho", Doxa Cuadernos de Filosofía del Derecho, España, núm. 42, 2019.

AMAYA, Jorge Alejandro, Marbury v. Madison: origen, argumentos y contraargumentos del control judicial de constitucionalidad, $2^{a}$. ed. Colombia-Bogotá, Ediciones Nuvea Jurídica, 2017.

${ }^{44}$ Cfr. CARCOVA, C. M., "Los jueces en la encrucijada: entre el decisionismo y la hermenéutica controlada", Jueces para la Democracia, España, núm. 24, 1994, pp. 36-37.

45 Sobre este punto, las sentencias de los jueces que protegen derechos fundamentales, también representan un motor de cambio jurídico y social. Véase: MUÑOZ MENDIOLA, J. C., "La contingencia del derecho y su uso alternativo", Revista de la Facultad de Derecho de México. UNAM, México, Tomo LXX, núm. 277, 2020, pp. 823-846.

46 Cfr. BARAK, A., Un juez reflexiona sobre su labor: el papel de un tribunal constitucional en una democracia, cit. p. 33. 
ATIENZA, Manuel, Curso de argumentación jurídica, Editorial Trotta, España, 2016.

BARAK, Aharon, Un juez reflexiona sobre su labor: el papel de un tribunal constitucional en una democracia, trad. de Estefanía Vela Barba, Suprema Corte de Justicia de la Nación, México, 2008.

BÖCKENFORDE, Ernest Wolfgang, Estudios sobre el Estado de derecho y la democracia, trad. de Rafael Agapito Serrano, Editorial Trotta, España-Madrid, 2000.

CARCOVA, Carlos María, "Los jueces en la encrucijada: entre el decisionismo y la hermenéutica controlada", Jueces para la Democracia, España, núm. 24, 1994.

CASAL HERNANDEZ, Jesús María, Las transformaciones del constitucionalismo y la justicia constitucional, Editorial PorrúaIMDPC, México, 2017.

DRIVER, Justin, "The constitutional conservatism of Warren Court", California Law Review, EE UU, vol. 100, núm. 5, 2012.

EPSTEIN, Lee y LANDEM, William E., "Was There Ever Such a Thing as Judicial Self-Restraint? California Law Review, EE UU, vol. 100, núm. 557, 2012.

FERRAJOLI, Luigi, La democracia a través de los derechos. El constitucionalismo garantista como modelo teórico y como proyecto político, trad. de Perfecto Andrés Ibáñez, Editorial Trotta, Madrid, 2014.

FIX ZAMUDIO, Hector, "La legitimación democrática del juez constitucional", en Ferrer Mac-Gregor, Eduardo y Molina Suárez, César (coords.), El juez constitucional en el siglo XXI, UNAMSCJN, México, 2009.

GARCÍA JARAMILLO, Leonardo, Activismo judicial y dogmática de los márgenes de acción: una discusión en clave constitucional, Instituto de Estudios Constitucionales del Estado de Querétaro, México, 2016.

GARCÍA PELAYO, Manuel, "El status del Tribunal Constitucional", Revista Española de Derecho Constitucional, España-Madrid, vol. 1, núm. 1, 1981.

GONZÁLEZ ORTÍZ, Beauregard, "El concepto de política pública en la administración pública norteamericana", Revista de Administración Pública. Escuela Graduada de Administración Pública, Puerto Rico, s.f., s.n.

GUASTINI, Riccardo, Estudios de teoría constitucional, trad. de Miguel Carbonell, México, IIJ-UNAM-Fontamara, 2011.

---Teoría e ideología de la interpretación constitucional, 2a. ed., trad. de Miguel Carbonell y Pedro Salazar, IIJ-UNAM-Editorial Trotta, México, 2010. 
HENKIN, L., "Is there a political question doctrine?", The Yale Law Journal, EE UU, vol. 85, núm. 5, 1976.

HERRERA, Carlos Miguel, "La polémica Schmitt-Kelsen sobre el guardián de la Constitución", Revista de Estudios Políticos, España, núm. 86, 1994.

JOSEPH FAVOREU, Louis, "La constitucionalización del Derecho", Revista de Derecho, Chile, vol. 12, núm. 1, 2000.

KLATT, Matthias, Hacer el Derecho explícito. Normatividad semántica en la argumentación jurídica, trad. de Francisco J. Campos Zamora, Madrid-España, Marcial Pons, 2017.

MANILI, Pablo Luis, Marbury v. Madison: reflexiones sobre una sentencia bicentenaria, México, Biblioteca Porrúa de Derecho Procesal Constitucional, 2011.

MCCLOSKEY, Robert G., "Reflections on the Warren Court", Virginia Law Review, EE UU, vol. 51, núm. 7, 1965.

MUÑOZ MENDIOLA, J. C., "La contingencia del derecho y su uso alternativo", Revista de la Facultad de Derecho de México. UNAM, México, Tomo LXX, núm. 277, 2020.

OSSA HENAO, Mario, La discrecionalidad judicial, Colombia-Bogotá, Leyer Editores, 2015.

OSUNA, Néstor, "Las sentencias estructurales", en Bazán, Víctor, (ed.), Justicia constitucional y derechos fundamentales No $5 . \mathrm{La}$ protección de los derechos sociales. Las sentencias estructurales, Konrad Adenauer Stiftung, Colombia, 2015.

POSNER, Richard, How Judges Think, Harvard University Press, London, 2008.

REY MARTÍNEZ, Fernando, "El Dr. Bonham's case y su aporte a la creación de la Judicial review" en Manili, Pablo Luis (Coord.), Marbury vs Madison reflexiones sobre una sentencia bicentenaria, Editorial Porrúa-Instituto Mexicano de Derecho Procesal Constitucional, México, 2011.

SCHOTTEN, Peter, "Marbury v. Madison, Rightly Understood, Perspectives on Political Science, EE UU, vol. 33, Issue 3, 2004.

TUSHNET, Mark, "Law and prudence in the law of justiciability: The transformation and disappearance of the political question doctrine", North Carolina Law Review, EE UU, vol. 80, 2002.

WARREN, Charles, "The Story Marshall Correspondence (18191831)", The William and Mary Quarterly Historical Magazine, EE UU, segunda serie, vol. 21, núm.1, 1941. 